\title{
Maestras Normalistas de la Escuela Profesional y de Artes y Oficios del Estado de México: honorables, de buen comportamiento y buenos servicios (1889-1910)
}

\author{
Normal Teachers of the Escuela Profesional y de Artes y \\ Oficios del Estado de México: Honorable, of good Behaviour and \\ good Services (1889-1910) \\ Edith Castañeda Mendoza ${ }^{1}$
}

\begin{abstract}
Resumen
En el presente artículo se hace un breve recorrido por la historia de las maestras decimonónicas de la Escuela Profesional y de Artes y Oficios para Señoritas del Estado de México. Se analizan los requisitos para ingresar y permanecer en la docencia y las diferencias entre las maestras de la sección normal y las de artes y oficios, así como los criterios de evaluación, premiaciones y castigos. Desde la historia social, se narra la vida cotidiana en el plantel de estas mujeres encomendadas a construir la "nación moderna" en las postrimerías del Porfiriato. Para tales efectos, se empleó una diversidad de fuentes primarias recuperadas de la biblioteca, hemeroteca y archivos históricos del Estado de México. Se concluye como un estudio que abona a la emergente historia de las maestras de educación normal y técnica mexiquense: pinceladas que develan el amplio lienzo del pasado de la mujer en el ámbito profesional.
\end{abstract}

Palabras clave: historia de la educación, mujeres, educación y Estado, proyecto educativo.

\begin{abstract}
This article makes a brief journey into the nineteenth century, thus deepening on the history of teachers at the Escuela Profesional y de Artes y Oficios, for ladies, of the Estado de México. This paper analizes the requirements for admission and permanence, as well as the differences between the teachers of the normal section and those of the arts and crafts as well as the evaluation criteria, distinctions and punishments. From the perspective of social history, the everyday life of these women - thaught themselves to build a "modern nation" in the late stages of the Porfiriato era - is narrated. For this aim, a diversity of sources from the libran, the newspaper library and the historical archives of the Estado de México was employed. This study aims to contribute to the emergent history of teachers of normal and technical education at the Estado de México: the aim is to make a small contrutibution which shows aspects of the broad topic of women's past in this professional field.
\end{abstract}

Abstract

Keywords: History of Education, Women, Education and State, Educational project.

\footnotetext{
${ }^{1}$ Instituto Iberoamericano de Historia de la Educación y Cultura Escolar. Doctora en Humanidades UAM-I, línea Historia. Miembro del Sistema Nacional de Investigadores (SNI). Líneas de investigación: Historia de la educación de la mujer, educación histórica. Correo electrónico: edithcastuam@gmail.com
} 


\section{Introducción}

El prestigio de la Escuela Normal del Estado de México ha sido adquirido no sólo por su importante historia dentro de la formación del magisterio, sino también por el profundo respeto y renombre de algunas de sus maestras. El plantel nace en el ex convento del Carmen, tuvo diversos cambios de nombre y distintos proyectos educativos; sin embargo, en este artículo se analiza la educación de la mujer en el periodo en el que el plantel llevó por nombre "Escuela Profesional y de Artes y Oficios para Señoritas" (1889) y hasta que cambia de sede a la avenida Independencia (1910), al volverse coeducativa. A continuación se analiza, específicamente, la vida cotidiana de las maestras del plantel. Se revisan su trayectoria educativa, los requisitos de ingreso, los esquemas de nombramiento, el perfil profesional o técnico y, finalmente, los criterios de evaluación y premiación.

El estudio permite conocer algunas realidades por las que atravesaron estas mujeres, que fueron verdaderas vicisitudes para afiliarse como docentes en el plantel. Tuvieron que cumplir diversos requisitos para perdurar y no ser despedidas. Se les exigió educar con virtudes del bello sexo, disciplina y buenas costumbres, así como enseñar con el más alto estándar de virtud femenil y docente: con el buen ejemplo. La negación al "buen servicio docente", recato y disciplina, implicó su inmediato despido y el señalamiento social. Por el contrario, si se cumplía cabalmente la labor de enseñar con valores morales, cívicos y disciplinarios, se les enlistó y premió públicamente como maestras de oro, de plata o de bronce.

El reconocimiento o descalificación de la labor docente de las mujeres, en el siglo XIX, es sustancial para comprender las dinámicas educativas actuales de nuestra realidad en materia de género. El siglo XIX "se trata de un momento importante en la historia de México, cuando es grande la obsesión por ingresarse al "concierto de las naciones", término al uso, con el que se busca afanosamente un orden..." (Tuñón; 2008: 12), es decir, la vigilancia de actitudes públicas para las maestras tuvo una suerte de espejo. Fueron reproductoras de las limitaciones de lo femenino que se visualizaron en acciones sociales:

Estas normas se aprecian en la legislación, en los textos científicos y pedagógicos, en las reglas de la vida social incluyendo la de cortesía, distinción y buen gusto. Con todas ellas se rige lo que el cuerpo debe mostrar, esconder, controlar y expresar en público e implican la vigilancia de minucias del terreno de los gestos, los comportamientos, el lenguaje corporal y los atuendos. (Tuñón; 2008: 12)

Las maestras de la Escuela Profesional y de Artes y Oficios para Señoritas atendieron a las alumnas internas (quienes vivían y estudiaban en el plantel) y externas (quienes sólo estudiaban en este centro escolar y salían cada día a sus hogares). Había también maestras que sólo educaron a las alumnas internas, estas fueron las profesoras de cocina y planchado. Tuvieron 
la encomienda de instruir a las señoritas que vivían en el centro escolar sobre las labores femeniles "útiles" para su cuidado en el internado y como actividad propia de su género.

Es importante señalar que las maestras que trabajaron en este proyecto educativo figuran entre las primeras del Estado de México en educar a mujeres profesionistas en las carreras de farmacia, comercio y telegrafía. Incluso las profesoras de lavado y planchado pasaron a la historia como las primeras instructoras en la última escuela Profesional y de Artes y Oficios del siglo XIX mexiquense.

Las maestras del plantel no sólo instruyeron con métodos correctivos y estrictos a sus alumnas, a ellas también se les corregía y/o premiaba como método de control del modelo pedagógico escolar de la época. Es un siglo que, en palabras de Geneviéve Fraisse y Michel Perrot, fue "sombrío y triste, austero y restrictivo para las mujeres...concibió la vida de las mujeres como desarrollo de una historia personal sometida a una decodificación colectiva precisa y socialmente elaborada" (Geneviéve y Perrot en Georges y Perrot; 1991: 2).

Fueron irrevocables los mandatos e instrucciones que recibieron de sus superiores que, la mayoría de veces, fueron varones o de su directora. Tuvieron el designio de educar con firmeza y de obedecer con acato: educadas y vigiladas con control y orden de las reglas morales. Servir y obedecer fueron actitudes apreciadas en el magisterio decimonónico. Desde la docencia como principal agente socializador, "se intenta ansiosamente precisar una moral social, establecer un conjunto de valores que rijan las relaciones humanas, con énfasis en el control social y en la conformación de una "fábrica de género" ... que garantice el orden" (Nash citado en Tuñón; 2008: 13). La educación reglamentaria en el Reglamento de la Escuela Profesional y de Artes y Oficios para Señoritas estipuló:

Obedecer, sin observación las órdenes que la Directora les diere, especialmente cuando sea en presencia de las alumnas, sin perjuicio de hacer en lo particular y de una manera respetuosa a la propia Superiora, después de cumplir sus mandatos, las representaciones que crean fundadas en razón, cando estimen injusta o arbitraria la orden recibida. ${ }^{2}$

\footnotetext{
${ }^{2}$ Archivo Histórico de la Escuela Normal para Profesores del Estado de México (AHENPEM), Toluca, Estado de México, Memoria del informe presentado ante la Honorable Legislatura del Estado de México (1897- 1901), Reglamento de la Escuela Profesional y de Artes y Oficios para Señoritas, Anexo núm. 34, Título IX. De los Profesores en general, p. CL.- CLII.
} 


\section{Requisitos de ingreso y permanencia. Mujeres honorables, de buen comportamiento y buenos servicios}

La instrucción que impartieron las profesoras estuvo en la batuta de la directora del plantel. Su desarrollo profesional fue notablemente más visible en la impartición de materias relacionadas con el ámbito pedagógico, labores femeniles, economía doméstica y urbanidad, pues la mayoría de las materias científicas eran impartidas por varones. Evidenciar las diferencias de la vida profesional de las mujeres en las escuelas decimonónicas permite abrir una ventana hacia la constitución de las desigualdades entre los géneros en las instituciones formadoras de docentes, considerando que la historia cultural se interesa por los procesos y lo que caracteriza a un grupo frente a otro, la manera en que constituye "un conjunto de diferencias significativas". (Tuñón; 2008:15)

En esta lógica de contrastes, podemos comprender algunos espacios de la docencia del plantel en la sección de párvulos. Ahí, las plazas docentes no fueron ocupadas por varones, pues su significado social fue "inapropiado para hombres" y asignado a las maestras de la escuela por asociación a la maternidad. Entre 1897 y 1901, sólo ejercieron como profesoras Matilde Silicia (para el año preoperatorio), Sofía Andresen (para el primer año), Silvina Jardón (el segundo año), Petra López (como auxiliar 1) y Enriqueta Veytia (como auxiliar 2). Entre 1897 y 1901, se encontraban dentro de la plantilla de la Escuela Profesional y de Artes y Oficios para señoritas 50 profesoras y 16 profesores.

En la Sección de Párvulos encontramos a cinco maestras: Matilde Sicilia, Sofía Andresen, Silvina Jardón, Petra López y Enriqueta Veytia. En la Sección de Primaria Elemental, sólo tres: Isabel Botello, Luz Herrera, Asunción Macedo y Laura Colón. A cargo de la Instrucción Primaria Superior María Hernández y Trinidad Medero. La lista con mayor número de profesoras es la Sección Normal.

La asignación de docentes a las diferentes secciones del plantel: Párvulos, Instrucción Primaria Elemental, Instrucción Primaria Superior, Sección Normal y técnica, obedece a la construcción de una cultura escolar que comparte hábitos, costumbres, valores, creencias y representaciones de género para las maestras y los maestros. El 100\% de la plantilla docente para las primeras secciones antes mencionadas (párvulos, primaria elemental y superior) fueron atendidas por mujeres. Sin embargo, para la sección Normal, eran 24 hombres y 27 mujeres.

Las materias que ofrecían los varones estuvieron relacionadas con Derecho, Comercio, Química, Física, Geometría, Cosmografía, Literatura, Historia, teneduría de libros, higiene general, encuadernación y fotografía, mientras que las profesoras ofrecían clases de bordado, flores, ropa de niño, costura, modas, piano, canto, telegrafía, Pedagogía, Psicología, educación social, moral y práctica, Geografía, economía doméstica, inglés y francés, o eran ayudantes de 
la clase de fotografía. Para Julia Tuñón, la cultura escolar se vincula con las llamadas mentalidades, las ideologías y el poder, este:

...no siempre se impone eficientemente en forma vertical y que circula en todas direc-
ciones abracando terrenos diversos, ligando lo público, lo privado y lo secreto, y para
eso requiere una negociación entre modelos y prácticas ideológicas y mentalidades,
entre imaginarios y representaciones. Lo femenino se construye por contraste con lo
masculino, como principios excluyentes que se implican uno al otro. (Tuñón; 2008: 15)

Las clases asociadas a las ciencias exactas estaban impartidas por varones, quienes en algunas ocasiones trabajaban también en la Escuela Normal para varones o de Artes y Oficios del Instituto Científico y Literario. Los profesores que ofrecieron clases entre 1897-1910 fueron Gabriel Durán, quien impartió el $1^{\circ}$ y $2^{\circ}$ año de francés; Ramón Covarrubias, profesor de Geometría general; Rafael Araujo, impartiendo Física y Química; Rafael N. Navas, con la materia de Cosmografía y nociones de mecánica; Margarito González, quien ofreció la asignatura de Historia americana y patria; Fernando Arriaga en la asignatura de Botánica, Zoología y Lógica; Enrique Schulz, impartiendo Geometría Universal y Felipe N. Villa Rello frente a la clase de Literatura Preceptiva. ${ }^{3}$

Otros varones frente a grupo ofrecieron clases relacionadas al comercio interior, exportación e importación. La asignatura de correspondencia mercantil e Historia del comercio fueron impartidas por Alejandro Herrera; este profesor también ofreció la materia de teneduría de libros al igual que el profesor José María Arzate y Vilchis. Gonzalo Pichardo enseñó la materia de encuadernación.

Feliciano Nava dio la clase de Química, Rafael Araujo Física general para el $2^{\circ}$ curso de la carrera de farmacia y Luis Ducloux, al igual que Isidro Martínez, enseñó dibujo a las señoritas del plantel. Sobresale el profesor Antonio Tapia, quien quedó registrado como el único profesor del idioma náhuatl. Algunos de los profesores del platel estuvieron registrados como Licenciados, tal es el caso de Daniel Guardiola, quien impartió la asignatura de Derecho comercial o el caso del mismo Eduardo Villada al frente de la clase de Economía política y Derecho constitucional.

Sin embargo, se pueden encontrar el caso de Tepoxina Pintado, quien es la única maestra que ofreció una asignatura no relacionada al ámbito de la práctica pedagógica, las labores domésticas o artísticas femeniles. Ella impartía las clases de Física del globo comprendiendo nociones de Cosmografía, Mineralogía y Geología, así como la asignatura de Derecho usual. Françoise Mayeur ha descrito la educación femenina en Europa para las postrimerías del siglo

${ }^{3}$ AHENPEM, Toluca, Estado de México, Memoria del informe presentado ante la Honorable Legislatura del Estado de México (1897- 1901), pp. CLXXXIII y CLXXXIV. 
XIX. Esta fue muy similar a la ofrecida por las maestras del plantel: "como la enseñanza está destinada a niñas, lo único que se tomó en consideración en las respectivas asignaturas es lo que se juzga "útil" para ellas en función de postulados implícitos. No se les enseñará filosofía, tanto miedo se tenía de formar "mujeres sabias". Se les impone la tradición que aspiraba a dar a las niñas una enseñanza prioritariamente literaria...". (Françoise; en Georges y Perrot; 1991: 32).

Las maestras transmitieron asignaturas "femeninas", como "en los buenos internados de Europa de la época”, como lengua, historia natural, dibujo, las labores de aguja y gimnasia. Fue común que algunas profesoras de la escuela impartieran más de una asignatura y en más de una sección del plantel. Tal es el caso de Sofía Andresen, dando clases en el primer año de la sección de párvulos, al igual que la materia de Ceografía americana y patria en la sección Normal. Las profesoras que ejercieron la docencia en el plantel, por al menos cinco años, son: Porfiria Morales, Ignacia Inclán, Sara Guzmán y Guadalupe Rodríguez.

Ser docente de la Escuela Profesional y de Artes y Oficios para Señoritas significó ser ejemplo a seguir para sus alumnas. Joan W. Scott, citado por Tuñón, argumenta que lo femenino se construye y atribuye a las mujeres a través de discursos y representaciones que influyeron en su día a día, con el ejemplo. Como modelos de disciplina, se enfrentaron en un trabajo cotidiano lleno de reprimendas. Su vida profesional, su salario y descuentos estaba directamente controlado por el gobernador en turno.

Los conceptos normativos, las nociones políticas y las diferencias institucionales permiten identificar la construcción de lo femenino para las maestras en las escuelas del siglo XIX. La aceptación o negación de sus solicitudes por parte de funcionarios públicos las ubica en el camino de la heteronomía y dependencia. Tal es el caso de la maestra Virginia López del Valado, a quien se le emite una carta desde la Secretaría General Sección de Instrucción Pública, Departamento de Escuela Primaria y Profesional 18 de octubre de 1912, comentando lo siguiente:

Habiendo comprobado el motivo que le impidió concurrir al desempeño de sus clases en este establecimiento, durante la 2da quincena de julio y 14 de agosto últimos, el C. Gobernador ha dispuesto se le reintegre, como ya se ordena, la cantidad de $\$ 8444$ cs., que por tales faltas le descontó. ${ }^{4}$

En otras ocasiones, el gobernador Vicente Villada, en calidad de gobernador constitucional del estado, envía a través de su Secretaría General Sección de Instrucción Superior y Justicia un escrito a la subdirectora de la Escuela Normal para Profesoras y de Artes y Oficios, informándole que se había concedido a la Señorita Emilia Dubavry de Millotl una licencia de ocho días

${ }^{4}$ AHENPEM, Toluca, Estado de México, fondo correspondencias, sección Dirección, vol. 42, 1912. exp. 122. 
para separarse de las clases que desempeñaba en el plantel, quedando en su lugar la Señorita María Despana. ${ }^{5}$

Nueve días después, esta misma secretaría escribe nuevamente a la subdirectora y le confirma que ha sido enterada del regreso a las funciones de dicha profesora. Sin embargo, se presentaron muchos casos de concesiones a profesores y profesoras de licencias para retirarse momentáneamente del plantel, por días, semanas y meses y, en todos los casos, la subdirección de la escuela notificó al gobierno estatal a través de su Secretaría Ceneral.

Las peticiones se hicieron también directamente a la dirección del plantel, ejemplo de ello fue la solicitud de una licencia pedida por la señorita Inés López en 1899 para retirarse, expresado de la siguiente manera: "arreglar un asunto de familia y no pudiendo precisar el tiempo en que pueda usar la causa me obliga a hacerlo, suplico se sirva elevar al Superior Gobierno mi solicitud para que me conceda una licencia por tiempo indefinido, sin goce de sueldo". ${ }^{6}$

La solicitud sí fue presentada al Secretario General de Gobierno el 23 de junio de 1899. Dos días después de la solicitud de Inés, la Secretaría General decidió que: "el mismo Gobernador tuvo a bien acordar que no puede nombrarse profesora que sustituya a la expresada señorita López por tiempo indefinido y por lo mismo, se le acepta su renuncia". ' La respuesta del gobernador aclaró que se le hiciera de conocimiento a la profesora Inés y, en cambio, se dispuso que, de haber compatibilidad, sería la señorita Trinidad Medezo quien cubriera la plaza vacante. La profesora no aceptó, pues expresó: "como mi objeto no es separarme de una manera definitiva del empleo que desempeño, sino sólo pido una licencia y esta no se me pudo conceder, suplico que se le haga manifestar a la superioridad que remito mi solicitud y continuo en mi encargo si para ello no hubieran surgido dificultades".

Esta profesora pudo permanecer en el plantel, pero sin concedérsele la licencia para atender las demandas familiares que la aquejaron. No obstante, resulta relevante mencionar que esta licencia de tipo indefinido sí se otorgó al Lic. Agustín Morales, profesor de la clase de pedagogía, quien además disfrutó de un sueldo de $97 \not \subset$ diarios cuota líquida; este maestro fue sustituido por órdenes de la Secretaría de Gobernación por el Lic. Pascual Morales.

Las relaciones de poder también se dieron entre mujeres del plantel. Por ejemplo, a la directora, en algunos casos, se le concedió la posibilidad de elegir su planta docente. Ejemplo de ello se presentó en el año de 1900, cuando la Secretaria de Gobiernos concedió proponer a un

\footnotetext{
${ }^{5}$ AHENPEM, Toluca, Estado de México, Relativo a licencias concedidas a algunos profesores para separarse de sus clases, Escuela Normal para Profesoras y de Artes y Oficios, serie cursos, sección gobierno, caja 1882-1943, 1899, exp. 294.

${ }^{6}$ AHENPEM, Toluca, Estado de México, Relativo a licencias concedidas a algunos profesores para separarse de sus clases, Escuela Normal para Profesoras y de Artes y Oficios, serie cursos, sección gobierno, caja 1882-1943, 1899, exp. 350.

7 AHENPEM, Toluca, Estado de México, Relativo a licencias concedidas a algunos profesores para separarse de sus clases, Escuela Normal para Profesoras y de Artes y Oficios, serie cursos, sección gobierno, Caja 1882-1943, 1899, exp. 294.

${ }^{8}$ AHENPEM, Toluca, Estado de México, Relativo a licencias concedidas a algunos profesores para separarse de sus clases, Escuela Normal para Profesoras y de Artes y Oficios, serie cursos, sección gobierno, caja 1882-1943, 1899, exp. 350.
} 
profesor de canto quien gozaría de un sueldo de $32 \not \subset$ diarios cuota líquida (incluso respetando la clase propuesta por la dirección y el horario para ofrecerla). Así, nueve días después, la dirección propuso y fue aceptado para la clase al profesor Julio Bernal. ${ }^{9}$

\section{Nombramientos de la planta docente}

La Secretaría General de Justicia e Instrucción Pública fue la dependencia gubernamental que se encargó de proponer, a nombre del Gobernador, a los maestros y maestras que ofrecieran clases en la Escuela Profesional y de Artes y Oficios. En algunos casos, la directora tenía esta facultad por instrucción del gobernador estatal. Sin embargo cabe mencionar que, anteriormente, estas disposiciones venían de esta misma institución, que en este tiempo se Ilamó Secretaria General Sección de Hacienda y Justicia.

Para que un maestro o maestra de la Escuela Profesional y de Artes y Oficios para Señoritas tomara posesión en este cargo, debía aprobar un estricto protocolo entre las órdenes del gobierno estatal y la administración escolar. Este formulismo implicó como principio la solicitud escrita del gobernador constitucional del Estado de México, el General José Vicente Villada, a través de su Secretaría General de Justicia e Instrucción Pública, en la que se le notificaba a la directora del plantel el nombramiento del profesor o profesora, la asignatura a impartir y, en algunos casos, el sueldo a percibir. El nombramiento o sustitución de profesores se emitía desde la Secretaría General de Hacienda y Justicia hacia el Secretario General del Estado, a la que se le solicitaba, por ejemplo: la "Toma de posesión de su cargo al C. Gallopín administrador de este plantel a quien en este nombramiento sustituya al C. Emilio Román" 10

En 1894, se le solicitó por escrito a la directora de la Escuela Normal para Profesoras "nombrar a la Señora Rosa lloya profesora de las clases de inglés y economía doméstica de la Escuela...con un sueldo de cincuenta centavos diarios", y al maestro "Juan García, profesor de lógica, economía política y principios de Derecho Constitucional en el Plantel; igualmente, fue nombrado el C. Ignacio Montero profesor de Raíces Latinas, psicología y moral a este propio plantel". ${ }^{11}$

Así, el ejecutivo del Estado - a través de su Sección de Hacienda y Justicia - solicitaba por escrito a la dirección del plantel, en 1893, nombrar al catedrático de español al Sr. Lic.

\footnotetext{
${ }_{9}^{9}$ AHENPEM, Toluca, Estado de México, Relativo a licencias concedidas a algunos profesores para separarse de sus clases, Escuela Normal para Profesoras y de Artes y Oficios, serie cursos, sección gobierno, Caja 1882-1943, 1899, exp. 350

${ }^{10}$ AHENPEM, Toluca Estado de México, Nombramiento de profesores, sección gobierno, serie maestros, caja 18911922, vol.3, exp. 113 .

${ }^{11}$ AHENPEM, Toluca Estado de México, Nombramiento de profesores, sección gobierno, serie maestros, caja 1891-1922, vol.3, exp. 113 .
} 
Vicente Landa a quien se le concedió una licencia por causa de conformidad, respondiéndole la dirección que comenzaría a trabajar con un sueldo de veintisiete centavos por jornada diaria. $^{12}$

Para 1895 los maestros de talleres tuvieron un protocolo muy similar de integrarse a la plantilla docente. Su contratación dependió de la comunicación entre la Secretaría General Sección Hacienda y Justicia (que obedecía instrucciones expresas del señor gobernador del Estado de México), así como la dirección del plantel. Los nombramientos eran respondidos de inmediato por la dirección: como versa el siguiente párrafo: "por la comunicación de esta fecha, queda enterado al Señor Gobernador que el C. Ignacio Senovio Suárez comenzó el día 13 de enero para la apertura del taller de fotograbado en esta escuela". 13

El análisis de los expedientes de nombramientos de los profesores permite conocer cuáles fueron los criterios para contratar a los docentes del plantel y una marcada diferencia de ingresos por género y las materias que ofrecieron. Cabe mencionar que los profesores varones de talleres como el de fotografía (por ejemplo, Agustín Palacios) ganaba casi el doble que una maestra de la clase de geografía de México en la carrera de Profesora de Instrucción Primaria de 3ra clase (por ejemplo Sofía Andresen). Estas diferencias de ingresos por género también se pudieron identificar en el sueldo de la maestra Virginia L. De Vallado,

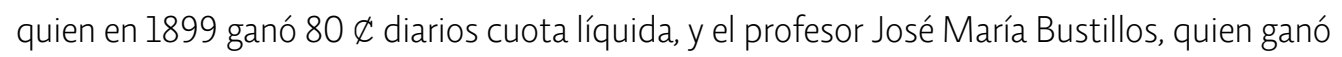
en el mismo año y por la impartición de la misma materia (recitación) \$1.33 diarios cuota líquida, uno de los sueldos más elevados de este plantel. Un dato relevante es el del sueldo más alto entre 1899 y 1900, que fue para un profesor del taller de fotografía, Agustín Palacios, quien ganó $\$ 1.76$ diarios cuota líquida. ${ }^{14}$

Algunas profesoras, ayudantes de clase, ganaron menos que las titulares. Ejemplo de ello es Luz Zamora, quien ganó exactamente la mitad (32 Øॄ diarios cuota líquida) que Sofía Andresen ( $64 \not \subset$ diarios cuota líquida), profesora titular de la clase de geografía de México. Los auxiliares de clase, al igual que los ayudantes, ganaron $32 \not \subset$ diarios cuota líquida. Sin embargo, la señorita Ignacia Inclán, profesora auxiliar de la clase de canto, ganó más que la

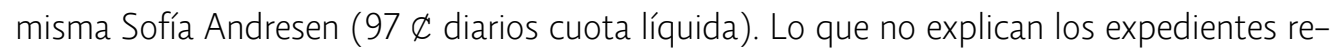
visados, son las causas de las diferencias de ingresos..$^{15}$

Los profesores contratados entre 1899 y 1900, que ganaron los ingresos más elevados, fueron tres mujeres y tres hombres: María Legorreta, profesora de 2do año de normalistas de 3 ra clase (96 Øॄ diarios cuota líquida); Trindad García, profesora de Psicología moral y

\footnotetext{
12 AHENPEM, Toluca Estado de México, Nombramiento de profesores, sección gobierno, serie maestros, caja 18911922, vol.3, exp. 113.

${ }^{13}$ AHENPEM, Toluca Estado de México, Bases para el contrato con los tres monarcas sobre flores y confecciones, sección gobierno, serie maestros, caja 1891-1922, vol.3, exp. 8, p. 5.

${ }^{14}$ AHENPEM, Toluca Estado de México, sección gobierno, serie maestros, caja 1891-1922, 1897, exp. 176, f. 42.

${ }^{15}$ AHENPEM, Toluca Estado de México, sección gobierno, serie maestros, caja 1891-1922, 1897, exp. 176, f. 289.
} 
educación cívica (96 \૮ diarios cuota líquida); Señora Merced Chiapa, auxiliar en la clase

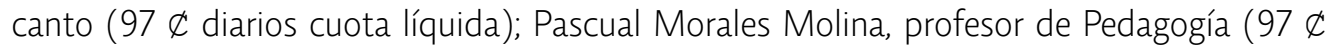
diarios cuota líquida); Feliciano Nava, farmacéutico (96 \૮ diarios cuota líquida) e Ignacia

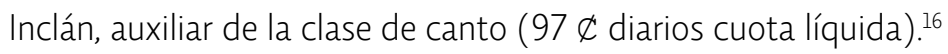

Analizando los ingresos que las maestras percibieron según una carta enviada a la Secretaría General de Gobierno el 30 de junio de 1899, podemos visualizar cantidades que no se contemplaron menores a los $32 \not \subset$ diarios, que fue la cuota mínima de contratación identificada en los expedientes de los docentes e ingreso mayores a los \$3, siendo la señora Zárate quien ganó más en este año (aún no se identifica su expediente para corroborar su actividad en el plantel). ${ }^{17}$

\section{Perfil de maestras de cocina, lavado y planchado}

Dentro del proyecto educativo existió una notable diferenciación entre sus maestras, pues, aunque a todas se les encomendaba el cuidado y vigilancia de reglas morales y la inculcación de los principios de virtud, sentimientos de bondad, rectitud, amor y esmero en los trabajos cotidianos de sus alumnas, sólo algunas podían impartir educación en las carreras profesionales y otras, por su perfil, sólo podían ser profesoras de cocina y lavado y planchado.

La profesora de lavado y planchado sólo tenía que "ser una señora de edad adulta de buenas maneras, enérgica y de reconocida competencia en el oficio". ${ }^{18}$ Sus responsabilidades recaían en actividades de labores cotidianas y para ello no se les solicitaban títulos, sólo experiencia y carácter firme. En cambio, las profesoras de las carreras profesionales debían tener título profesional para ejercer.

Puede considerarse que a estas maestras no se les solicitó un documento que acreditara sus conocimientos, ya que bastaba con que en la práctica ejercieran con pulcritud los mandatos de limpieza y cocina de las alumnas y transmitieran sus aprendizajes no sólo con el ejemplo, sino guiando en la cotidianidad las labores de higiene y los más estrictos hábitos de urbanidad. A ellas les bastó ser limpias, ordenadas, contar con conocimientos bastos en técnicas modernas de higiene, poder y mando ante las alumnas para ser contratadas.

En el año de 1898, el sueldo de estas profesoras de lavado y planchado fue de \$4 mensuales y los alimentos. Entre algunos de sus deberes estuvieron los de manejar la lavadora

\footnotetext{
${ }^{16}$ AHENPEM, Toluca Estado de México, sección gobierno, serie maestros, caja 1891-1922, 1897, exp. 176, f. 320

${ }^{17}$ AHENPEM, Toluca, Estado de México, serie correspondencias, sección dirección, vol. 57, 1912, exp. 122.

${ }^{18}$ AHENPEM, Toluca, Estado de México, Reglamento de la Escuela Profesional y de Artes y Oficios para Señoritas, Memoria del informe presentado ante la Honorable Legislatura del Estado de México (1897- 1901), Anexo núm. 34, Título XI. De la maestra de lavado y planchado, Art. 15, p. CL.- CLII.
} 
(máquina de lavar) con precisión y enseñar a las alumnas tanto el uso de esta, como la manera de lavar por el sistema antiguo, así como la de planchar, encarrujar y ahuevar. ${ }^{19}$

Debía, por tanto, tener especial cuidado de que las educadoras aprendan debidamente a lavar la ropa de color con separación de la blanca, sin que la una se destiña ni la otra se manche o escupa. Esta maestra tenía la encomienda, desde lo práctico, de enseñar a lavar las ropas de lana y el uso de los ingredientes que tienden a mejorar el lavado, tales como las lejías, el carbonato de sosa cristalizado, el álcali, el bórax, el petróleo y otros. Cuidar de que la ropa que está en enjebe no se enmohezca, que las coladuras se hagan con la debida limpieza y que las prendas puestas al sol no sean pisoteadas, no enlodadas, ni sacudidas por el viento.

El reglamento escolar versa muy particularmente sobre las profesoras de cocina y las de lavado y planchado, quienes debían vivir en el establecimiento y quienes desempeñaran labores de orden, escrutinio y preparación de los alimentos que diariamente consumieron las señoritas del Plantel, así como del cuidado de la ropa y apariencia de las alumnas.

La preparación en actividades propias de su sexo que recibían las señoritas por parte de sus profesoras no siempre fue a través de clases o talleres, sino por medio de lecciones cotidianas al momento de vestirse, peinarse, convivir y relacionarse entre sí, además de espacios de la escuela como el de la cocina. La cultura escolar, cargada de roles propios para mujeres, permisos específicos y restricciones, permite conocer un fragmento de los discursos, las normas y las representaciones con los que la educación formal e informal construyeron las bases de la formación diferenciada para mujeres y hombres en las postrimerías del Porfiriato.

Las maestras de lavado y planchado del plantel educaron con clases prácticas necesarias para subsistencia en la escuela y que formaba mujeres apegadas a su rol de género. Pero siempre se inculcaron, desde la docencia: "hábitos de trabajo, puntualidad, moralidad, decencia, aseo, buen trato y manejo sociales, siendo ejemplo de los fines que perseguía la educación normalista con respecto a la socialización escolar" (Hurtado en Arredondo; 2003: 287). Es decir, teniendo en cuenta que, al concluir sus estudios en la escuela Profesional, serían ejemplo vivo de buenas costumbres y hábitos para cuando estuvieran a cargo de la educación de la infancia mexiquense.

Tal es el caso de la atribución a la cocinera del establecimiento, a quien se le encomendaba "dar diariamente lecciones de arte culinario a las alumnas que señale la dirección, enseñándole de una manera clara, metódica y gradual, tanto la preparación y condimentación en los alimentos, como la especial de helados y repostería" ${ }^{20}$

${ }^{19}$ AHENPEM, Toluca, Estado de México, Relativo a la supresión de la 2 da galopina y nombramiento de una lavandera, sección correspondencias, fondo, sección dirección, Vol. 5, 1898, exp. 257.

${ }^{20}$ AHENPEM, Toluca, Estado de México, Reglamento de la Escuela Profesional y de Artes y Oficios para Señoritas, Título IX. De la maestra de cocina, Memoria del informe presentado ante la Honorable Legislatura del Estado de México (1897- 1901), Anexo núm. 34, Art. IX, 1902, pp. CL.- CLII. 
Uno de los pormenores que no debe descuidar la Profesora en cuestión, fue que las alumnas practicantes ejecuten todas las acciones que les encomiende con la mayor pulcritud y esmero. El sólo hecho de tener la posibilidad de comer sanamente y, aún más, con postre y saber las técnicas de su hechura, pudo significar una extrañeza y deleite de algunas alumnas internas del plantel quienes, como se ha indicado anteriormente, en su mayoría, no gozaban de estos placeres en sus humildes hogares.

Estas maestras podían gozar de aumentos salariales si el gobernador lo disponía, como lo muestra el oficio enviado por la Secretaría General de Instrucción y Justicia número 1099 fechado el 5 de octubre de 1898, en el que se solicita a la directora de la Escuela Normal para Profesoras y de Artes y Oficios que se les aumente el sueldo a diez pesos a la quincena. ${ }^{21}$

La instrucción en las artes de lavar y planchar, se inculcaron para atender a la imagen de mujer moderna que implicó el mantenimiento de una casa impecable: a estas mujeres se les enseñó a través de la materia de lavado y planchado a contener la ropa blanca: sábanas, manteles, servilletas, toallas, paños de cocina. Las maestras se formaron bajo roles femeninos para transmitir, en palabras de Foucault, "el orden de las cosas", de los códigos de género. Educaron para el lavado, para la limpieza de la ropa personal del marido y la propia: "se consideraba a una mujer de gobierno a la que estaba orgullosa de la lencería que ha sabido procurarse, que ha confeccionado y arreglado metódicamente". (Huerta en Herrera; 2002:193).

Por tanto, la enseñanza de la higiene se hizo prioritaria para los programas de estudio de las escuelas normales como la de Toluca, la cual incluyó a su plantilla docente a maestras que mostraran los adecuados procesos de la higiene y el cuidado de las prendas. Sin embargo, resulta pertinente mencionar que estas profesoras tuvieron distintas vivencias profesionales a las de otros estados de la República, como en Estado de Puebla, ${ }^{22}$ donde fueron a la escuela para poder ejercer la docencia como lavanderas o cocineras:

Cada sociedad construye un imaginario sobre el cuerpo cruzado de tensiones. Para Michel Foucault cada periodo histórico permite tan sólo un marco limitado de percepción propia lo que puede ser concebido, dicho y/o visto desde ahí se construyen los límites de lo que se muestra (y se vive) y de lo que se nombra (y se escucha), los filtros de la miradas y de la palabra que incluyen informaciones, creándose el mundo de lo obvio, pero también el de lo secreto, lo reprimido, lo prohibido, produciendo los códigos de la sensibilidad, las sentimentalidad y la mentalidad, la organización de conocimiento, los esquemas perceptivos, los valores y jerarquías otorgados o, para

\footnotetext{
${ }^{21}$ AHENPEM, Toluca, Estado de México, Relativo a la supresión de la 2da galopina y nombramiento de una lavandera, sección correspondencias, fondo, sección dirección, Vol. 5, 1898, exp. 258.

22 Para conocer más sobre las maestras de lavado, se recomienda ver el trabajo de Ana María Dolores Huerta Jaramillo, "Las lavanderas van a la escuela", en Herrera Feria, María de Lourdes (Coords.), La educación técnica en Puebla durante el Porfiriato: la enseñanza de artes y oficios, Benemérita Universidad Autónoma de Puebla, Puebla México, 2002.
} 
decirlo con este autor, "el orden de las cosas" en el que cada ser humano se reconoce como ente social. (Tuñón; 2008: 21)

Las maestras enseñaron actividades relacionadas a la mujer educada para el hogar. La exigencia por estudiar y atender la morada se formó también en los espacios educativos públicos y gratuitos. Así, durante el siglo XIX, la higiene, como responsabilidad de las mujeres, se fue haciendo presente tanto en ámbitos institucionales como familiares. Se les educó en casa y en las escuelas para limpiar y mantener higiénicos los espacios donde habitaron ellas y los otros.

Durante el siglo XIX, los espacios laborales de las mujeres estuvieron relacionados a la extensión de las labores en sus viviendas: lavando, planchando, cuidado de los menores y los enfermos; que supuso, en la práctica, una prolongación del trabajo doméstico, y que además le permitió el contacto con las demás mujeres y educarse entre sí para compartir los estereotipos heredados.

El oficio de lavar ropa, antiguo en las actividades cotidianas femeniles, estuvo relacionado con el infortunio, comenta Ana María Huerta: "muestra a la mujer del sector popular en una condición de desgracia, mal alimentada, sujeta a duros trabajos... para ayudar al marido en el sostenimiento de la familia, llena de pesares, recorriendo todos los días enormes distancias para llevar los alimentos al esposo que trabajaba como cargador, obrero, o albañil y quien, por lo regular, pagaba el servicio a puñetazos". (Huerta en Herrera; 2002: 186)

En la escuela Profesional y de Artes y Oficios del Estado de México no se les dio el taller de lavado y planchado, sólo se les enseñó a mantener la higiene personal y del área que ocuparon en la escuela. Fue una educación de aseo para sí, y no para trabajar del oficio de lavar y planchar ajeno.

\section{Perfil de maestras de los talleres}

Las profesoras de los talleres fueron instructoras de las artes y oficios que se ofrecieron anualmente a estudiantes internas y externas del Plantel. Cada año se podían cambiar los talleres en función de las propuestas de enseñanza para ese año efectuadas por los profesores y las profesoras de esta sección. La directora y su cuerpo académico de docentes decidían cuál era el taller que sería abierto en función de las necesidades del plantel y de los cursos existentes. En algunas ocasiones, ya iniciadas las clases, se solicitó al gobernador Villada que se permitiera abrir un taller distinto al programado para efectos prácticos como cubrir una solicitud de hechura de prendas y costuras.

Las maestras de esta sección no sólo ofrecieron una preparación técnica femenil a sus alumnas, también impartieron diversos conocimientos artísticos como piano, canto, solfeo, 
canto superior y formaron academias de música y hasta estudiantina del plantel. Entre los talleres de oficios se pueden encontrar bordado, flores, dibujo, encuadernación, modas, confección, flores y costura a mano, caligrafía, taquigrafía, inglés, modas, flores, fotografía, encaje catalán, costura a máquina, modas y confección, flores artificiales, bordado y corte, costura blanca, dibujo y bordado, por mencionar algunos.

Impartieron al menos 22 talleres distintos las profesoras de esta sección, con un interés constante, a lo largo de cuatro años de duración de la normal. La diversidad de contenidos que se manejaron en los talleres nos hace pensar que estas mujeres fueron educadas en sus casas o por maestras particulares para impartir estas clases o, incluso, que alguna egresada de los talleres regresara a compartir sus aprendizajes. Esta investigación aún no ha encontrado los estudios de cada profesora de los talleres de la Escuela Profesional y de Artes y Oficios.

No está de más mencionar el taller de inglés. Es sumamente importante, ya que implica que este idioma (en pleno auge en el siglo XIX y XX) pudo ofrecerse también a señoritas que no estudiaron en alguna carrera profesional del plantel. Se pudieron preparar en el idioma como un arte (para leer o escribir en inglés, ya que los siglos XIX y XX fueron años de proliferación de textos en inglés y francés, sobre todo durante el Porfiriato) o como un posible oficio.

No está de más recordar que el ideal educativo femenil del Estado de México fue educar a mujeres útiles y serviciales, pero inteligentes y educadas, ya fuera a nivel profesional y en artes y oficios o en la enseñanza del inglés, lo cual figuró prioritario para tales fines, sobre todo para formar mano de obra calificada, que no sólo supiera realizar el trabajo técnico, sino que supiera manejar las máquinas y tener acceso a las tecnologías venidas del extranjero.

No obstante, hace falta conocer si la formación en los talleres de inglés de la Escuela profesional y de Artes y Oficios cumplió con este cometido de educación técnica también para las mujeres, o sólo impartió las nociones elementales del idioma para la comunicación y comprensión de las obras modernas de moda. En un seguimiento de los talleres en la institución durante siete años, se encuentra que se atendieron a 838 alumnas de los talleres, 119 alumnas en promedio anual. Entre los años de 1897 y 1901 se registró a nueve maestras de talleres del plantel, lo que puede significar que cada una de estas maestras atendía, al menos, a 13 alumnas en promedio por clase de manera constante a lo largo de un cuatrienio.

Las maestras registradas fueron Ernestina Baillet, para el taller de Canto Superior, Josefina López, impartiendo modas y confecciones, Porfiria Morales con costura en máquina y Aurelia Murguía, enseñando bordado. El taller de costura en blanco estuvo a cargo de Consuelo Soto V. de López, el de ropa de niño a cargo Luz Zamora y, el de flores artificiales, tuvo como responsable a María de Jesús Ponce de León. 
En relación a la autonomía y autoridad de elección de los recueros de los talleres, se puede mencionar que no tuvieron injerencia en los productos que se elaboraron en sus clases. Las profesoras de los talleres "no podrían recibir el valor de las prendas particulares que se hicieren, ni el de aquellas que se destinen a la venta individual. Los mismos profesores tienen la obligación de remitir mensualmente a la Dirección de Rentas una noticia pormenorizada y valorada de los objetos entregados durante el mes del almacén." ${ }^{23}$

Las maestras de los talleres tuvieron, como ya lo mencionamos antes, la encomienda de formar mujeres decorosas, recatadas y virtuosas a través de: "exigir enérgicamente a las señoritas educadas que desempeñen sus tareas bien, pronto, en silencio y guardando la compostura que corresponde a personas decentes". ${ }^{24}$ Su encomienda principal no fue activar las conciencias reflexivas, subversivas y de ruptura de orden hegemónico. Ellas recibían, en sus aulas, a mujeres indígenas, pobres, huérfanas, hijas de comerciantes, maestros, abogados y viudas y a todas las formaban con un molde de orden, disciplina y laboriosidad femenil. Su intención fue la de homogeneizar e integrar a un mismo proyecto educativo de educación Normal, profesional y técnico a las mujeres en el Estado de México.

Un mérito de las enseñanzas en los talleres del plantel fue haber sido educadas de manera distinta a la realización de las famosas labores propias de su sexo. Los talleres de costura, bordado, fabricación de flores y otras producciones de objetos decorativos, aunque generalmente muy mal pagados, permitieron tener la posibilidad de alejarse de la herencia sociocultural de la maternidad. Ello ayudó a que las mentalidades evolucionaran, aunque lentamente predominaba en el ideario educativo la convicción de que las mujeres no tenían las mismas aptitudes intelectuales que los varones.

\section{Criterios de evaluación, premiaciones y castigos: maestras de oro, plata y bronce}

Los criterios que evaluaron a las profesoras como acreditadas y distinguidas vinieron de la Ley Orgánica de Instrucción Primaria (en sus artículos 152, 153 y 154), que estableció quiénes podían obtener recompensas por sus buenos actos en su labor docente. La construcción de imaginario de la maestra normalista del Estado de México, nace de alguna manera en estas dinámicas docentes donde se premiaron roles femeninos que fueron construyendo las realidades de su vida profesional y la cultura escolar que rebasa lo onírico y se vive en reali-

${ }^{23}$ AHENPEM, Toluca, Estado de México, Reglamento de la Escuela Profesional y de Artes y Oficios para Señoritas, p. CLXVIII.

${ }^{24}$ AHENPEM, Reglamento de la Escuela Profesional y de Artes y Oficios para Señoritas, Título XI. De la maestra de lavado y planchado, p. CL.- CLII. 
dades. Tuñón argumenta que "El imaginario no puede ya entenderse como fantasía o ficción, sino como conjunto de imágenes, símbolos, metáforas y representaciones que constituyen la realidad, porque... cada sociedad se da representaciones de sí misma mediante ideasimágenes que le permiten establecer modelos a partir de su propio "caudal simbólico" para hacer inteligible al mundo" (2008: 24). Las maestras consideradas de oro debieron ejercer bajo esquemas simbólicos de honor en el cargo de profesora de establecimientos oficiales, sin que hubiera habido en él interrupciones que las motivadas por licencias concedidas a causa de enfermedad justificada. Maestras honorables, de buen comportamiento y buenos servicios.

El artículo 106 del capítulo XIV de la Ley Orgánica de la Escuela Profesional y de Artes y Oficios para Señoritas versa sobre la facultad de gobierno del Estado en considerar el buen comportamiento y los buenos servicios de los profesores para promoverlos a plazas escolares mejor dotadas o a los empleos del ramo de Instrucción Pública para los que hubieren demostrado buena aptitud. En el artículo 107 se menciona que los profesores que hubieran sido nombrados inspectores escolares se consideraran, para el cómputo del tiempo de sus servicios, como profesores en servicio activo.

No sólo se asignaban los espacios de trabajo desde el orden gubernamental sino la asignación de menciones especiales por su desempeño en la tarea de educar. Eso lo podemos analizar del artículo 108, que estableció que las medallas serían de tres clases: la primera clase correspondiente a los treinta años de servicios, será de oro y de forma circular, midiendo 0,"035 de diámetro por 0,"002 de espesor. En el anverso llevará una inscripción: "Premio de constancia de mérito pedagógico".25

La jerarquía de género se visibilizó en las premiaciones y castigos de las maestras. Se otorgaron medallas de segunda y tercera clase, respectivamente, a las maestras que corresponden a diez y veinte años de servicio. "Serán de plata las primeras y de bronce las segundas con igual troquel y las mismas dimensiones que las de primera clase. Se llevarán sobre la parte izquierda del pecho y suspendidas en la solapa por una cinta de seda de 0,07 de largo por 0"03 de ancho para las medidas de primera clase; la cinta será roja. Para las de segunda, blanca; y, para las de tercera, verde". ${ }^{26}$

La colocación de estas medallas estaba verificada por el mismo Gobernador del Estado quien, en distritos foráneos, encomendaba a los jefes políticos en su representación a la colocación de dichos reconocimientos. La violencia simbólica penetró la cultura escolar del

\footnotetext{
${ }^{25}$ AHENPEM, Toluca, Estado de México, Memoria del informe presentado ante la Honorable Legislatura del Estado de México (1897-1901), Anexo núm. 33, Ley Orgánica de la Escuela Profesional y de Artes y Oficios para Señoritas, p. CXXXIX.

${ }^{26}$ AHENPEM, Toluca, Estado de México, Memoria del informe presentado ante la Honorable Legislatura del Estado de México (1897- 1901), Anexo núm. 33, Ley Orgánica de la Escuela Profesional y de Artes y Oficios para Señoritas, p. CXXXIX.
} 
plantel y, ejerciendo una violencia real y simbólica, no sólo se puso énfasis en las premiaciones, sino también en los castigos. Las maestras fueron supervisadas desde el ejecutivo a través de la Ley Orgánica del plantel. "Las penas a las que los profesores se hacían acreedores consistían en amonestaciones, extrañamientos, multas, suspensiones de empleo o sustituciones". ${ }^{27}$ Además, serían impuestas por las autoridades locales en términos del reglamento de la escuela espontáneamente o a noción fundada de los inspectores del ramo, jefes políticos o presidentes municipales, proporcionando la magnitud de la pena y la gravedad de la falta que la motivare. La historia cultural permite identificar las dinámicas implícitas y explícitas de la cotidianidad. Así podemos hacer inteligible la representación del mundo magisterial, de la cultura de lo femenino en las aulas mexiquenses del siglo XIX y de la interpretación (parcial) de lo que fue una maestra de la época. A pesar de las condiciones diferenciadas por género, la herencia magisterial mexiquense se conserva hasta el momento como "sembradoras de saberes", "constructoras de nación" y ejemplo para las educandas (futuras maestras).

Estas mujeres representan lo que María de Lourdes Alvarado llamaría maestras que "superaron los diversos obstáculos que, hasta hace poco, habían impedido profundizar en su conocimiento, entre los que destacan la pervivencia de antiguos y arraigados prejuicios hacia la educación profesional de la mujer, pero, sobre todo, la escasa importancia que durante décadas prestaron a la educación de la mujer". (Alvarado; 2004: 4).

\section{Conclusiones}

Los proyectos donde participaron profesionalmente las mujeres como maestras Ilegaron con mayor firmeza durante el Porfiriato. Con ideales de una nación "homogénea" comenzaron a construir, desde las escuelas normales, el "espíritu nacional" que comprendía la integración de la población, sujeta a un mismo gobierno y habitando un mismo territorio, con rasgos similares, costumbres y tradiciones visiblemente destinadas a conformar la identidad nacional.

La educación de la mujer comienza a tomar fuerza en la formación de señoritas y se da prioridad a la educación Normal y técnica enfocada exclusivamente a las labores femeniles. Se abre un espacio de inserción educativa federal, pero se limitan desde condiciones de género las posibilidades de las mujeres para su desarrollo educativo y consecuentemente, en el ámbito laboral. La educación Normal se postula como la principal carrera profesional destinada para las mujeres, relacionada directamente con los roles del cuidado de los infantes y la maternidad: características consideradas como natas de ellas.

${ }^{27}$ AHENPEM, Toluca, Estado de México, Memoria del informe presentado ante la Honorable Legislatura del Estado de México (1897-1901), Anexo núm. 33, Ley Orgánica de la Escuela Profesional y de Artes y Oficios para Señoritas, p. CXXXIX. 
De esta forma, el perfil de maestra de la Escuela Profesional y de Artes y Oficios para señoritas (1889-1911) nace de un afán de acatar las disposiciones gubernamentales de orden Federal, ya que el Estado de México, de donde pertenece este plantel, tuvo una importante comunicación y apoyo del ejecutivo Federal con sus gobernadores porfiristas (José Zubieta y José Vicente Villada).

La escuela desarrolló, a través de su reglamentación, planes y programas de estudio a las últimas generaciones de Profesoras de Instrucción Primaria, profesoras de Instrucción Elemental (párvulos), licenciadas en Farmacia, Comercio y Telegrafía y estudiosas de artes y oficios femeniles de finales del siglo XIX y principios del XX. Este proyecto educativo (ya que la Normal sigue existiendo hasta la fecha) representa la herencia normalista del Estado de México y es el último intento por educar a las mujeres en planteles distintos a los varones.

A través de planes y programas estrictos, disciplinarios y de corte moralista (cívico y nacionalista), se pretendió formar mujeres mexiquenses en dos perfiles: el técnico y el profesional. El perfil técnico estuvo estrictamente relacionado a la adquisición de conocimientos de artes y oficios femeniles. A través de la enseñanza de talleres con conocimientos del bello sexo y para roles del hogar o labores artísticas de pintura, música o canto, las señoritas de estos cursos lograron educarse en ámbitos utilitaristas para las labores femeniles y no para el ejercicio de un trabajo como operarias técnicas en empresas o industrias de su comunidad. Las habilidades aprendidas en los talleres del plantel sólo les permitieron adquirir virtudes y gracias femeniles como bordar, tejer, zurcir, dibujar y de manualidades. No obstante, es importante referir que hubo talleres de los que pudieron obtener conocimientos útiles para insertarse al mercado de trabajo inmediato, como los talleres de telegrafía, encuadernación, inglés y confección.

Las mujeres que estudiaron artes y oficios estuvieron lejos de participar del proyecto de modernización del país, su preparación en el plantel y los talleres que se les ofertaron las imposibilitaron de participar de la industria o las empresas que nacían en el Estado de México. La oferta educativa de artes y oficios para mujeres del Estado de México siguió patrones de educación sexista, aceptando en lo implícito de su oferta educativa que la industria, el campo y los talleres reclaman los brazos fuertes del hombre para llevar adelante sus medios de progreso y la multiplicación de la riqueza pública, mientras que el comercio y las labores del hogar y los servicios debían colocarse en manos de una mujer modesta, dócil, educada, inteligente, instruida y de intachable moral.

Los resultados en las carreras profesionales fueron distintos. La Escuela Normal del Estado de México se reputó como una de las más importantes formadoras de maestras del siglo XIX (prestigio que se conserva hasta la fecha). La Escuela Profesional y de Artes y Oficios nace con el discurso del gobernador sobre la importancia de la educación Normal, quien contempló que la instrucción superior para las mujeres era indispensable para la cul- 
tura y perfeccionamiento de la sociedad, así como para el triunfo del individuo - vencer las adversidades de ingreso y permanencia y lograr egresar de la institución.

La educación en la sección normal de este plantel configuró la herencia magisterial del Estado de México, pero no fue recibida con buenos ojos por algunas personas de la sociedad civil y del clero católico. Se condenó a la mujer moderna por ser frívola y ligera: subsumida por la moda, triste, nerviosa, sexuada, sensual, envidiosa, exhibicionista, bailadora, enredada en líos amorosos; condenada a no casarse y, por ende, a ser infeliz. Las egresadas de este proyecto Normalista formaron parte de las primeras generaciones de mujeres en búsqueda de empoderamiento, espacios públicos y valoración de su trabajo fuera del hogar. Sigue siendo un campo fértil el estudio particular de su vida y obra. Hay tela de dónde cortar, ya lo demostró Milada Mazant, escribiendo múltiples libros de una maestra mexiquense: Laura Méndez de Cuenca.

\section{Referencias bibliográficas}

\section{Archivos}

AHENPEM, Memoria del informe presentado ante la Honorable Legislatura del Estado de México (18971901), Reglamento de la Escuela Profesional y de Artes y Oficios para Señoritas, anexo núm. 34, Título IX. De los Profesores en general, Oficina Tipográfica de Gobierno en la Escuela de Artes y Oficios. Toluca, Estado de México, 1902.

AHENPEM, fondo correspondencias, sección dirección, vol. 42, Toluca, Estado de México, 1912.

AHENPEM, Relativo a licencias concedidas a algunos profesores para separarse de sus clases, Escuela Normal para Profesoras y de Artes y Oficios, Toluca, Estado de México, serie cursos, sección gobierno, Caja 1882-1943, 1899.

AHENPEM, Nombramiento de profesores, Sección Gobierno, serie Maestros, caja 1891-1922, vol.6.

AHENPEM, Relativo a faltas de asistencia de los Señores Profesores, Escuela Normal para Profesoras y de Artes y Oficios.

AHENPEM, Nombramiento de profesores. Sección Gobierno, Serie Maestros, Caja 1891-1922, Vol.3.

AHENPEM, Bases para el contrato con los tres monarcas sobre flores y confecciones, sección gobierno, serie maestros, caja 1891-1922, vol.3.

AHENPEM, Reglamento de la Escuela Profesional y de Artes y Oficios para Señoritas, Memoria del informe presentado ante la Honorable Legislatura del Estado de México (1897- 1901), Anexo núm. 34, Título XI. De la maestra de lavado y planchado, Art. 15, Toluca, Estado de México, 1902. Oficina Tipográfica de Gobierno en la Escuela de Artes y Oficios.

AHENPEM, Relativo a la supresión de la 2 da galopina y nombramiento de una lavandera, Sección correspondencias, fondo, sección dirección, vol. 5, Toluca, Estado de México, 1898.

AHENPEM, Ley Orgánica de la Escuela Profesional y de Artes y Oficios para Señoritas, Memoria del informe presentado ante la Honorable Legislatura del Estado de México (1897- 1901), Oficina Tipográfica de Gobierno en la Escuela de Artes y Oficios. Toluca, Estado de México, 1902. 


\section{Bibliografía}

Alvarado, María de Lourdes (2004), La educación superior femenina en el México del siglo XIX. Demanda social y reto gubernamental, Editorial Plaza y Valdez.

Huerta Jaramillo, Ana María Dolores (2002), "Las lavanderas van a la escuela”, en Herrera Feria, María de Lourdes (Coords.), La educación técnica en Puebla durante el Porfiriato: la enseñanza de artes $y$ oficios, Benemérita Universidad Autónoma de Puebla, Puebla México.

Hurtado Tomás, Patricia (2003), "Formación de las mujeres para el magisterio en la Escuela Normal de Señoritas en el Estado de México, 1933-1934" en María Adelina, Arredondo, Obedecer, servir y resistir. La educación de las mujeres en la historia de México, Universidad Pedagógica Nacional, México.

Tuñón, Julia, Coord. (2008), Enjaular los cuerpos: normativas decimonónicas y feminidad en México, El Colegio de México, México PIEM, México Distrito Federal.

Geneviéve, Duby; Perrot, Michelle (1991), "Historia de las mujeres: El siglo XIX" en Historia de las mujeres en Occidente, editorial Taurus, España. 